\title{
The Digital Finance - opportunity of development in the new economy
}

\author{
Sorin BURLACU \\ Bucharest University of Economic Studies, Bucharest, Romania \\ sburlacu@amp.ase.ro \\ Ghenadie CIOBANU \\ National Scientific Research Institute for Labour and Social Protection, \\ Artifex University of Bucharest, Bucharest, Romania \\ gciobanu01@gmail.com \\ Victor Adrian TROACA \\ Bucharest University of Economic Studies, Bucharest, Romania \\ adrian.troaca@gmail.com \\ Carol Cristina GOMBOS \\ Bucharest University of Economic Studies, Bucharest, Romania \\ svegombos@yahoo.com.sg
}

\begin{abstract}
Information and telecommunications technology have altered society, the economy, and financial-banking activities globally in the previous few decades of development. The current stage of mass digitization is to design an increasing number of managerial, technical and technological tasks in all sectors of society and economic activity. It won't fall behind the financial sector, where digitalization is already having a rapid impact on the financial service sector, with a wide range of products, applications, and different processes, as well as the development of business models that transform the traditional way financial services are provided. Technological advances have occurred in all areas of economic and financial activity, from the boardroom to the regulatory and supervisory bodies in both private and public finance. In this post, we'll take a look back at the development of digital financial developers and rank them for the future.
\end{abstract}

Keywords: digital transformation, digital economy, digital finance, financial services, digitalization and information.

\section{Introduction}

In the face of an aging population and global competitiveness, we have three options: work harder, work really hard, or work smarter. We can't do all three (Bodislav et al., 2020). We'll very certainly have to execute all three, but only the third alternative ensures that Europeans' living standards will grow (Burlacu, Profiroiu \& Vasilache, 2019). The Europe 2020 strategy envisions two dimensions of economic growth, both quantitative and qualitatively focused on the maximum use of human resources. A modern economy built on knowledge and innovation can generate social cohesion. Inclusive economic growth includes fostering a high-occupation economy that can do so. Smart economic growth relies on cementing knowledge and innovation as true engines for future economic growth. There are action items in the Digital Agenda that must be implemented immediately in order for Europe to return to smart, sustainable, and 
inclusive growth (Burlacu et al., 2019). As our society and economy become increasingly digital, these ideas will serve as a framework for long-term societal and economic change.

Taking into consideration the objectives of the national strategy for Romania's Digital Agenda, which have been tailored to the country's current economic and social situation. National Strategy on the Digital Agenda for Romania focuses specifically on the information and communications technology sector, with the goal of promoting economic development and increasing Romania's competitiveness, both directly and indirectly, through direct actions such as the continuous improvement of the Romanian ICT industry and indirect actions such as increasing efficiency and lowering sector costs. boosting the productivity of the private sector by lowering administrative hurdles in connection to the state, improving the competitiveness of the Romanian labor force and other initiatives in Romania and abroad Romania's digital agenda should be guided by certain principles. The following are the core principles for Romania's Digital Agenda 2020, which will have an impact on all areas and lines of action in the country: Encouragement and attraction of taxpayers and enterprises, as previously stated, is the basic premise of every significant project in Romania, both strategically and operationally, and it is the underlying principle of every major initiative in Romania. Romania must recruit law-abiding residents who conduct legitimate business in order to maintain its position as a reliable investment destination and to keep its advantage in terms of highly qualified experts. Sustainable, open, and visible economic development are essential for closing the economic gap between Romania and other EU countries, as well as preventing probable disparities between living standards.

The digital economy is distinguished by three fundamental characteristics: it is a worldwide economy; it favours intangible products such as ideas, information, and relationships; and it is highly interconnected. These characteristics lead to the development of new market models for businesses that are based on the electronic network. The digital economy - as defined by Ciobanu et al. (2015) - is characterized by the following characteristics:

1. The infrastructure of the digital economy is number one. ICT has grown at a remarkable pace in recent years, both in the economy and in society as a whole.

2. The use of electronic markets. The following are the primary characteristics of electronic markets: new agents, new types of products and services, new business partnerships, and new communication and organizational methods.

3. Information - and knowledge-based products are available. The majority of products currently available on the electronic markets are intangible goods. Consumers, businesspeople, and middlemen are all examples of agents who are present on the markets.

5. Transformations in the macroeconomic environment and processes of globalization. Changes in the economy have an impact on macroeconomic variables, according to a macroeconomic perspective. The Internet helps to eliminate physical borders by promoting the progression of the globalization process as a whole.

6. The progressive and aggressive infiltration of the digital economy into the economic and social life of contemporary society in the twenty-first century.

The consequences of the global financial crisis have brought to light the fact that economic realities are altering at a faster rate than government policy. Millions of individuals have lost their jobs at the European level in recent years, and millions more have been affected by poverty and social exclusion to a larger extent.

What is digital financing and how does it work? (European Commission, 2020): A range of products, apps, procedures, and business models have been created as a result of new 
technologies' impact on the financial services industry. These innovations have altered the traditional approach of providing financial-banking services." Technologies have evolved in all sectors; we pay, move money, and make investments utilizing mobile technology, which includes a variety of innovative solutions." On September 24, 2020, the European Commission approved a package of digital funding measures. There is a digital financing plan as well as legislative suggestions on cryptocurrencies and digital resilience, as well as a revised retail payments strategy, included in the package. A competitive EU financial sector that offers consumers with access to innovative financial products while also assuring consumer safety and financial stability is the ultimate goal of this initiative. Digital finance, based on European principles and sending a signal of risk regulation, is something that should be encouraged in Europe. A number of factors have led to widespread and enthusiastic support for this goal in consultations with the European Commission held across Europe with stakeholders: "There are several priorities for the digital transformation of the financial sector in the EU member states," according to the European Commission. Four goals govern EU activity to achieve digital transformation by 2024, taking into account trends and objectives, as well as the overwhelming majority of replies to the public consultation that informed this plan." Defeating fragmentation in the digital single market for financing is the first objective, followed by providing European consumers with access to crossborder services and assisting European financial institutions in expanding their digital operations (Jianu et al., 2019).

It is also a priority to guarantee that the EU regulatory framework promotes digital innovation in the interests of consumers and market efficiency, as outlined in the previous priority. The third priority is the creation of a European financial data space for innovation-based promotion, which will be based on the European data strategy and will include increased access to data and data exchange in the financial sector. The European data strategy will also include increased access to data and data exchange in the financial sector (Negescu et al., 2020). It is necessary to adapt the regulatory framework to the EU in order to foster digital innovation. According to the Digital Financing Strategy, the goal is to guarantee that the EU's financial services regulatory structure is fit for the digital age. Through the establishment of a shared financial data space, it is possible to encourage data-driven innovation in the field of finance. Identifying and addressing the issues and risks related with the digital transformation (Radulescu et al., 2020). As previously stated, some issues and dangers associated with digital transformation of the financial industry are cross-cutting in nature because of the digital environment itself, while others are more specific to the different projects discussed above.

\section{Literature review}

"Digitalization is commonly referred to as the Fourth Industrial Revolution, which underlines that it is a necessary step in the search for humanity's good understanding of nature and the implementation of digital to better living and economic activities," according to Helwerda (2020). All of the technology we use today has its roots in scientific principles, particularly in physics. Temperature dynamics is a significant branch of physics. With the advent of the steam engine and the subsequent actions taken in order to enhance it, the development of what we now know as thermodynamics occurred (Orzan et al., 2020). The three laws of thermodynamics were discussed in depth during physics classes. We will stop at the second law of thermodynamics for the time being. It is possible to formulate the second law, which is the concept of entropy, in a variety of ways: Entropy can never be reduced in an isolated system (i.e., one that does not 
change in response to its surroundings). $\mathrm{S}$ is equal to zero in the following formula: $\mathrm{S}$ 0. This phrase makes use of two critical concepts:

(1) The quantity known as entropy can be defined as the amount of disorder in a system, as well as the level of disruption among the pieces that make up the system or the number of possible system configurations.

(2) It is critical to have an isolated system. A system will always have a competitive advantage. An rise in entropy is impossible in a closed system. The entropy of a system that is not closed can decrease. The provision of energy and the conversion of this energy have the potential to lessen the entropy of a system. This is referred to as self-organization (Bran et al., 2020). More order is being established in the system. If this order is to be maintained, a continual supply of energy is required; otherwise, the decay specified by the second rule will be implemented. Entropy and information are two different things. The task includes gathering information as well. Because there are more orders, more information about the system is required to explain it properly. In symbolic thinking, the manipulation of information is referred to as "information manipulation." During the course of mankind's evolution into a global civilisation, we acquired an increasing amount of information and organized it into organized files." "Abstract digitalization is about data and how it is used," Forte and colleagues (2019) contend. In the field of applied thermodynamics, it has long been a key topic." They "examine the impact of the present wave of digitalization on thermodynamics." According to the authors, As enormous amounts of data of varying nature and quality become readily available, the nature and quality of thermodynamic modeling and simulation evolves. The power and complexity of thermodynamic models and simulation approaches are increasing at an alarming rate, and new avenues for connecting them to data are becoming possible." They believe that "machine learning provides new perspectives when correctly coupled with classical thermodynamic theory," as the authors put it. There are several facets of digitalization in thermodynamics that are discussed in this article, including its advantages and disadvantages, as well as its prospects and threats. These are the authors' conclusions: "Digitization has had an impact on thermodynamics since computers became widely available, and computing power has opened up numerous new pathways in thermodynamics since computers became widely available. The core issue of digitization is data, particularly specifically how it is used in modeling and simulation processes. This is a critical problem in thermodynamics, and the present craze for digitization has a significant impact on thermodynamics in a variety of ways. This is not a reference to thermodynamic theory, which is infallible; rather, it is a reference to how thermodynamic theory is applied in modeling, simulation, and experiments. It is becoming increasingly difficult to distinguish between different sectors due to the proliferation of digital links, and the boundaries that were formerly clearly defined are becoming increasingly blurred. Computer simulation data can be coupled with experimental data to form hybrid data sets, which can then be used to construct models of the thermodynamic properties of real substances." The management of conflicting aims in the construction of thermodynamic models is accomplished through the use of multiple criteria optimization. At the advent of a new digital age in finance, Baxter (2021) is looking into how the financial industry will be affected by the evolution of the blockchain and cryptocurrencies. Our banking system is undergoing a digital transformation at the moment. Blockchain, which many experts consider to be "the most important invention on the Internet," has transformed the way in which we share value and information with one another. A new report, Digital financing: security chips and unlocking the true potential of blockchain technology, describes how integration of blockchain and security chip technology will transform the current financial infrastructure, 
allowing for significant improvements in efficiency, transparency, and security. Author Baxter Hines draws on his decades of experience in the financial industry to explain how asset digitization will reduce costs, increase flexibility, and pave the way for new business models and revenue streams for years to come. Using simple language and an easy-to-follow framework, Baxter Hines explains how asset digitization will lead to cost reductions, increased flexibility, and the creation of new business models and revenue streams for years to come.

The FAO report, according to Benni (2021), finds that "the COVID-19 pandemic has resulted in significant and persistent disruptions of the lives of people all across the world, including in poor and rich countries." Following the response of the public and commercial sectors to the COVID-19 issue, the overall digital financial inclusion process in developing nations has accelerated, particularly in a number of countries (such as those in West Africa) where it was still lagging behind regional trends. On the global market for finance, both developed and developing countries saw a significant increase in the subscription and use of fintech as people looked for alternative ways to manage the financial aspects of their lives in the wake of prolonged periods of blockade, physical separation, and disruption of livelihoods in both countries. It is the goal of Yang \& Youtang Zhang (2020) to investigate the impact and mechanism of digital financial inclusion on the long-term growth of small and micro companies in the People's Republic of China. The authors rely on data from companies that were listed on the New Third Board Market in China from 2011 to 2018 as well as the Beijing University Digital Financial Inclusion Index to compile their findings. The findings indicate that the advancement of digital financial inclusion contributes to the promotion of long-term growth of small and micro firms, particularly in private, high-tech industries and competitive marketplaces, as well as the development of digital financial inclusion in general. As a result of the research findings, it is concluded that, in the context of China's high-quality economic development, the continued promotion of digital financial inclusion and the transformation of the financial industry into a more environmentally friendly model can provide consistent financial support for the sustainable growth of small and micro enterprises as well as a healthy micro and macroeconomic environment. Danchev, Gatopoulos, and Vettas (2020), for example, state that Between 2014 and 2017, the amount of money spent on payment cards in Greece more than tripled. Their penetration was abolished with the implementation of capital controls in 2015, and their growth has continued to increase as a result of the measures contained in Law 4446/2016. According to the findings of the study, (I) the law had a significant, positive impact on the use of credit cards, thereby limiting the effects of macroeconomic factors and capital controls, and (II) the penetration of electronic payments had a significant, positive impact on tax compliance. Despite the fact that Greece's average level of card use has remained lower than the EU norm, there is significant variation between sectors and geographical areas. In conclusion, better targeted initiatives are required to further boost the prevalence of electronic payments, which would result in even bigger tax savings if they were implemented. Regulation 4446/2016, which encouraged the use of digital payment instruments and discouraged the use of cash, featured aspects that were both discouraging and incentivizing the use of payment cards and other digital payment instruments. As stated by Ozili (2018), "digital financing and financial inclusion have a number of benefits for users of financial services, for digital finance providers, for governments, and for the economy; however, a number of issues remain that can make digital finance work better for individuals, businesses, and government." Ananda, Devesh, and Lawati (2020) set out to research the elements that influence the adoption of digital banking by retail banking customers in order to provide recommendations. A theoretical model based on an extended technology acceptance 
model was constructed in order to conceptualize the relationship between many elements that influence the adoption of digital banking. The core information was gathered using a standardized questionnaire administered to 200 clients. The association between six independent factors was investigated through the application of the multiple regression equation. According to the findings of the study, awareness, online features, and perceived utility all have a statistically significant beneficial impact on the adoption of digital banking services. For example, Flyverbom (2017) notes that "the importance of digital technology for social and economic changes, as well as a growing emphasis on data collecting and privacy issues, have elevated the Internet to the status of a public and visible problem in global politics." A number of recent developments have heightened awareness that the current approach taken by governments and industry to regulation of the Internet and adjacent space technologies creates a variety of ethical concerns. (2019) says that: "The period of technological innovation is considered to be one of the important success elements for businesses, strengthening the life cycle of products, and this is especially true for those in the financial industry." Today, the demand for speed in the delivery of products or services, including those provided by financial services, particularly Islamic financial services, is extremely vital, especially in today's world. The rapidity of product or service delivery is critical in Indonesia, which has a distinctive terrain comprised of numerous islands, and is especially important for the financing of small and medium-sized firms (SMEs), which are the foundations of the country's economy."

\section{From computerization to digitization}

After all, according to Paulin (2018), the twentieth century has managed to bring humanity radically new knowledge in electronics, computing, and telecommunications technologies, giving rise to cyberspace as a channel for data exchange and storage, as well as a facilitator of new approaches to direct and control real world systems. As a result, new chances for process automation have been effectively applied in areas such as manufacturing, service provision, data modification, navigation, logistics, and many other disciplines, resulting in the creation of new possibilities through virtualization principles, respectively." At the moment, the computerization of government, in contrast to the digitalization of government, is only in the early stages of conceptual research and demonstration trials of the notion. The following are three notions that are founded on the computerization paradigm - that is, they embrace the principles of networking open files that are available as a matter of governing public governance systems - that are described in greater detail below. Information governance, liquid democracy, and the quantum budget are all topics that are being discussed. Establishment financial institutions and market participants have benefited from and/or implemented new services and business models as a result of the development of artificial intelligence, social networks, machine learning, mobile applications, distributed accounting technology, cloud computing, and big data analysis. Consumers and businesses profit from the respective technologies, as do financial institutions. These technologies enable consumers to gain access to financial services, provide a varied range of services, and contribute to the simplification of operations. They contribute to the removal of national barriers and the stimulation of competition in the following fields: (1) online banking, payments, and digital services; and (2) mobile banking, payments, and digital services. (2) Loans from one person to another (3) Investment services for individuals. There are a number of papers reviewed in the OECD publication (2018), with particular attention paid to the influence of digitalisation and information technology in the fields of financial markets, insurance, and private pensions. There is a discussion of the tools and policies required to meet the high difficulties of 
digitalization, which will result in improved results as well as better management of the risks associated with this process.

The problems of the interaction of the subsystems of the general national security system in the region are considered and investigated in the study by Ogorodnikov, Zaloznaia, and Borovskii (2018) on the basis of a systematic approach and analysis of economic security, as well as on the conceptual methods developed for the security of enterprises in the region. While at the same time, it is impossible to continue to assure the long-term development of regional firms without a fundamental understanding of integrated security theory as a whole. It is recommended that complete safety investigations of all types be conducted using a systematic approach and analysis. In this situation, it is required to transition from a task-based research to a systemic analysis of the objects and systems under investigation. This will allow for a clearer understanding of the internal linkages of the subsystems, including the economic security subsystem, in the process of the country's general system of national security's overall operation and functioning. In relation to this research topic, a method for substantiating the quality of enterprise security using the fuzzy sets device and a multi-criteria fuzzy method based on the Bellman-Zade principle is proposed, which allows you to choose an option that meets all criteria simultaneously to the greatest extent possible. When a comprehensive assessment of all types of security is formed using the substantive approach that has been developed, it will be possible to reasonably consider the influence and interaction of the subsystems of the general national security system, which will significantly increase the stability of the economic functioning of companies and organizations in the area.

\section{Methodology}

A bibliographic study of the topic was used to develop a methodology for studying it, and we also considered a thermodynamic approach to digitization because Entropy is a measure of the amount of chaos in a system, the amount of disturbance among the parts that make up a system, or the number of possible system configurations. Another concept that is deemed crucial is the shift from the stage of computerization to the stage of digitization. What exactly are the distinctions? How did digitalization arrive at this point in the long and complicated process of growth of both the digital economy and the digitization of specific domains of activity, such as in our case, digital finance, in the first place? Through evolution, new opportunities for process automation in areas such as production, service provision, data exchange, navigation, logistics and many other fields have been successfully implemented, opening the door to new possibilities through virtualization concepts, which have been successful in a variety of fields. Establishment financial institutions and market participants have benefited from and/or implemented new services and business models as a result of the development of artificial intelligence, social networks, machine learning, mobile applications, distributed accounting technology, cloud computing, and big data analysis. While this has resulted in major paradigm shifts in industry and the provision of services in the free market, the structures that underpin modern nations have largely remained unaffected by these technological advancements. Aiming to provide light on the contrasts between digitization and computerization as two distinctly different methods to system transformation, this article will examine the following points: The issue is set within the context of social governance, in which digitalization is the primary means of modernization and development. Specifically, the emphasis on digitization and the lack of progress toward computerization in this area of interest have been questioned, and the benefits of computerization have been brought to the public's attention.

DOI: 10.2478/picbe-2021-0036, pp. 392-405, ISSN 2558-9652 |

Proceedings of the $15^{\text {th }}$ International Conference on Business Excellence 2021 


\section{Governmental administration is being computerized}

Now, the computerization of governance, in contrast to the digitalization of governance, is only at the stage of conceptual research and proof trials of the notion. The following are three notions that are founded on the computerization paradigm - that is, they embrace the principles of networking open files that are available as a matter of governing public governance systems - that are described in greater detail below. Information governance, liquid democracy, and the quantum budget are all topics that are being discussed.

Following the description of Fintech, the part that follows looks at the digital technologies that are used in these breakthroughs. Following that, there will be an examination of the most significant applications of new technologies. This section addresses aspects of financial services that have been impacted by modern technologies, taking into consideration the framework defined in the previous article. What exactly is "Fintech"? In order to better understand the Fintech phenomena, this essay takes a step back in time to remind us that technology-based innovation in the financial services sector is not a recent phenomenon. It is more accurate to describe the developments that are now grouped under the "Fintech" umbrella label as the latest evolution of a structural development process that dates back to the liberalization of entry and ownership restrictions in the financial services sector during this period in the 1980s and 1990s. In addition, digital platform applications and new technology are revolutionizing the insurance industry. First and foremost, they alter the way insurance is obtained and provided. For example, insurance providers are now providing access to their products through mobile devices. P2P insurance also provides platforms via which individuals can organize their own groups of individuals with whom to share risk, allowing them to save money on insurance premiums. Operations. Technology can considerably increase the efficiency of processes and the efficiency with which financial institutions work across the board, as well as to prevent the occurrence of unexpected costs in all types of financial institutions. Increased automation has the potential to make everyday tasks easier to do. Communications. The way financial service providers engage with their customers is also evolving as a result of new technology. They are altering the way financial goods are advertised. Online advertisements are frequently targeted based on the profile of their viewers, which is derived from their online behaviour and browsing patterns. Following consumer engagement with a product or service, recurring messages can be targeted to each individual, for example, through texting reminders to make contributions to a savings plan or a pension fund, or to make payments on their credit card bills, among other things. Fintech advances have an impact on various aspects of financial activity and services. To understand the impact and implications of Fintech advances, there are three general approaches that can be used to tackle the problem. The first approach is to begin with technology such as distributed ledger technology (DLT), then examine the uses of this technology in financial services and the potential consequences that this technology may have. To do so, one must first examine a specific use, such as crowdfunding, and then assess the ramifications of that application in general. Beginning with an emphasis on the impact of these changes, such as the growth in cyber risk, and what these changes imply for certain policy objectives is the third approach of analysis. Efficiency in terms of operations. During the wave of mergers that followed financial deregulation, competition for savings intensified both inside and between financial services sectors, as well as between intermediaries in different financial services sectors. This phase was primarily concerned with consolidating and integrating financial services, both vertically and horizontally, between products and geographies, in order to achieve economies of scale and scope

DOI: 10.2478/picbe-2021-0036, pp. 392-405, ISSN 2558-9652 |

Proceedings of the $15^{\text {th }}$ International Conference on Business Excellence 2021 
in the financial services industry. The role of the intermediary. Oftentimes, debates concerning the digitalization of financial services revolve around the de-intermediation of financial service providers. However, these trends can also result in shifts in intermediation, or even the formation of whole new financial intermediaries. Using cryptocurrency for payment is a prime example of technical innovation that is undermining the business model of incumbent suppliers, as electronic payments are no longer required to travel through banks in order to be processed successfully. Peer-to-peer platforms alter the intermediate structure, with digital platforms that are suitable for both sides of the transaction taking the place of the traditional bank as a counterparty in the transaction. Speed. In the context of the digitization of financial services, the term "speed" has two meanings: it refers to both the speed with which activities are carried out and the pace with which change occurs. On the one hand, digital transactions can be completed far more quickly than they were previously feasible to do. This may also mean that consumers will spend less time reflecting on their purchases as a result of this. Accessibility. Consumer financial products and services have become more accessible as a result of the digitization of financial services, which has the potential to significantly reduce the financial exclusion of more vulnerable populations. The new models have previously targeted underserved market segments, with mobile banking services, in particular, bringing banking services to underserved market segments in developing nations, serving as an example. Consumer participation is important. Customer interfaces that are more user-friendly and make it easier for consumers to manage their finances have the potential to increase the amount of time they spend actively managing their finances, as well as provide new opportunities to engage consumers with technology, such as text messaging and video. However, these tendencies may also result in consumer disengagement, as the ease of trading may necessitate less vigilance on the part of the customer. Automation. As digital technology is being used in financial services, the reliance on algorithms and process automation is growing. While human involvement does help to lessen the likelihood of human mistake in some ways, the algorithms themselves rely on human input at the outset, thus this exposure is not totally avoided. Finance-related developments have structural ramifications. A number of critical components of the production and distribution of financial products and services are suggested by the discussion in the preceding section to be impacted by developments connected to new digital technologies, including All of these developments have an impact on the way in which investors and financial consumers interact with financial product providers.

The Organization for Economic Cooperation and Development (OECD) believes that two sets of policies are required to build a more resilient financial system that is capable of coping with disruptive financial innovations. Improvements to the financial services infrastructure are one set of initiatives being considered by the government. Other necessary measures are aimed at different types of inventions and are divided into three categories. In accordance with the findings of the OECD study (2018), "we believe that Open API standards in banking can promote competition by fundamentally altering the way consumers purchase banking services." Most notably, it promotes the entry into new business models that assist consumers in obtaining better value from existing banking products and moving between products without the need for consumers to exert significant effort in determining how alternative offers meet their requirements." According to the study, they demonstrate a way for the state, or rather an independent competition agency, to be entrepreneurial and exercise a vision of how digital innovation can make markets work better for consumers while remaining in line with the principles of competitive neutrality and impartiality. For competition agencies to be effective in carrying out competitive activity for consumers, the OECD report highlights that they should not 
be confined to investigating and resolving secondary supply issues. This is emphasized throughout the study. Effective markets require active and demand-enabled activity, and this necessitates much more than simply safeguarding them against mis-selling and other unfair tactics, as proven by open API standards, which are designed to facilitate such activity.

There are new possibilities. Government can drive current fiscal policy more efficiently by doing what we do today, but better - and can, in too short a time frame, conceptualize policy in novel ways - by doing things that we cannot and cannot do now. Increasing the efficiency with which governmental services are delivered. The use of digital technology can aid in the delivery of public services. First and foremost, governments may take use of increased capability to distribute critical information to the public. According to research, farmers' understanding of agricultural best practices and commodity pricing can be improved by exchanging information via text messaging on those practices and prices (Table 1).

Table 1. Use of electronic payment systems

With the use of electronic payment systems, bureaucratic waste has been reduced, tax savings created, and the supply of government benefits has been made more convenient.

\begin{abstract}
Following the digitization of payments in Haiti and the Philippines, for example, the transaction cost of several social assistance programs reduced by nearly or more than 50\% each transaction (Zimmerman, Bohling, and Rotman Parker 2014). Governments are increasingly relying on biometric technologies to broaden the scope of social benefits and enhance targeting of those benefits. Direct benefit transfer (DBT) is an Indian government program that was launched in 2013 and has drastically altered the system of delivering subsidies and benefits digitally. It has almost eliminated the high levels of theft and bribery that were typical following the country's civil war (Frydrych, Scharwatt and Vonthron 2015). When databases are linked between government agencies and relevant third parties, there are chances to broaden the scope of benefits available to citizens. It is often the case that efforts to alleviate poverty through redistribution are thwarted because many eligible persons do not sign up for benefits..
\end{abstract}

PICBE | 401

Source: Zimmerman, Bohling, and Rotman Parker (2014) and Frydrych, Scharwatt and Vonthron (2015).

With the expanded scope for the exchange of information on individual taxpayers and cross-border matching, it is possible that capital gains taxation will be imposed directly on shareholders, thereby eliminating the need for corporate tax to serve as a vehicle for withholding tax on final shareholders in the future. A new generation of technology that allows for the electronic tracking and labeling of individual consumer purchases could open the way for more innovative and progressive consumption taxation schemes, such as tracking (and taxing) consumption throughout the rest of one's life (Table 2).

\section{Table 2. The availability of high-frequency tax}

Tax decision-makers now have When it comes to policymakers attempting to stabilize the business cycle, access to high-frequency tax data, which opens up new possibilities such as enhanced revenue forecasts and budgeting.

daily fiscal data can be particularly useful because it allows them to monitor economic activity in real time, which can be very beneficial. Governments can use improved data storage and processing capacity to leverage the linkage of corporate tax revenues in order to foresee a crisis or monitor cash balances in order to better assess liquidity and lending requirements. 


\section{Discussions and results}

Consumers and investors will have more access to a wider choice of financial services, more innovative services, lower costs, and greater accessibility in terms of time and space under the conditions of establishing a digital society and digital economy. Access to these items will be made easier using interoperable digital identities, which will allow for remote and cross-border access. There has been widespread agreement among those who took part in the public consultation that consumers will face additional risks as a result of the technology of companies gaining market share in financial services. These risks could include the negative consequences of a potential reduction in competition. In order to effectively implement all parts of this strategic action, it is critical to make it easier for consumers to receive financial services while also addressing the dangers that they face.

It is critical to build a new framework for safe remote identification, faster access to public disclosures, and a new open funding system.

\section{Conclusions}

In today's economy and society, the revolutionary development of digitalization is occurring at the level of globalization, and this is changing both the global development as a whole and the economic development of regions, countries, economic agents, and educational institutions in a wide range of public sectors. Last but not least, there is the involvement of the financial sector, which, on the one hand, must be directly involved in financing and supporting digitalization initiatives, as well as the overall digitization of the entire financial-banking system, on the other hand. In this article, we set out to approach the process of digitization of the economy through the prism of thermodynamics, because digitization has had an impact on thermodynamics since computers became widely available, and computing power has opened up many new avenues in thermodynamics since computers became widely available. In light of the fact that data is the most important issue with digitization, as well as how data is used and interpreted in modeling and simulation - both of which are important topics in thermodynamics - and that the current high point of digitization has an impact on thermodynamics in a variety of ways, this does not refer to thermodynamic theory; rather, it refers to the use of thermodynamic theory in modeling, simulation, and experiments.

Establishment financial institutions and market participants have benefited from and/or implemented new services and business models as a result of the development of artificial intelligence, social networks, machine learning, mobile applications, distributed accounting technology, cloud computing, and big data analysis. Consumers and businesses, as well as financial institutions, profit from the respective technologies, which facilitate access to financial services, provide a varied range of services, and help to the streamlining of operations. Digital technologies contribute to the reduction of national barriers and the stimulation of competition in the following areas: (1) online banking, payments, and digital services; and (2) mobile banking, payments, and digital services. (2) Peer-to-Peer lending (3) Personal investing services are examples of such services. The COVID-19 pandemic had an impact on the recognition of the necessity for the development of electronic financial services. Advances in mobile money, financial technology services, and online banking have the potential to provide significant benefits to low-income individuals and small enterprises alike. Financial inclusion as a result of the widespread availability of digital financial services has the potential to drive economic growth. The issue of information security, as well as the security of digital systems, is a specific topic (cyber security). With the substantive approach that has been developed to form a 
comprehensive assessment of all types of security, it will be possible to reasonably take into account the influence and interaction of subsystems of the general national security system, which will significantly increase the stability of state management systems. This will include not only the influence of economic agents and financial institutions in the region but also the influence of economic agents, financial institutions, enterprises and organizations in the region. The need to develop new models of economic and institutional development that include the use of digital technologies would fundamentally alter paradigms in industries such as manufacturing, health care, education, and service delivery in the free market. Against this backdrop, the purpose of this contribution is to analyze the distinctions between digitization and computerization, which are two different approaches to the transformation of the economic and financial-monetary systems, respectively. In addition, digital platform applications and new technology are revolutionizing the insurance industry. First and foremost, they alter the manner in which insurance is obtained and provided. Mobile devices are now being used by insurance providers to provide access to their policies. $\mathrm{P} 2 \mathrm{P}$ insurance also provides platforms via which individuals can organize their own group of people with whom to share the risk, allowing them to reduce their own insurance costs.

Technology has the ability to considerably increase the efficiency of processes and the efficiency with which financial institutions work across the board, as well as to prevent the occurrence of unexpected costs in all types of financial institutions. Increased automation can help to make everyday tasks easier to do.

The way financial service providers engage with their customers is also evolving as a result of new technology. They are altering the way financial goods are sold to the public. A three-pronged strategy to understanding the impact and implications of Fintech advances might be used to approach the problem. The first step is to begin with technological advancements. Due to the fact that electronic payments no longer have to go via banks, the usage of cryptocurrencies as a payment method is an example of technical innovation that is undermining the business model of incumbent providers. In the context of the digitalization of financial services, the speed of transactions and operations plays an increasingly important role; this relates to both the speed of operations and the speed of change; transactions may be completed much more quickly than was previously feasible. Accessibility: The digitization of financial services has, in general, increased the accessibility of many consumer financial products and services, and it has the potential to significantly reduce the financial exclusion of more disadvantaged sections in our society.

Consumer engagement: New customer interfaces and the ease with which digital financial services can be used have the potential to increase the amount of time that consumers spend actively managing their finances. They also provide new opportunities to engage consumers with technology, such as text messaging and video, which has the potential to increase their financial literacy.

Risks associated with digital security: As our reliance on digital technology and financial services grows, so does the risk associated with digital security. Because of the increased connectivity to digital solutions, cyber security risks are not limited to financial systems technology. Cyber hackers are constantly on the lookout for weak places in networks and are increasing their number of entry points into networks. Data analysis, secrecy, and openness: Information technology has an impact on the acquisition of information, its analysis, and the transfer of that information. The advancement of digital technology has significantly expanded the ability of advanced analytics to be applied in the financial services industry. 
The digitization of public services has the potential to significantly improve the delivery of the complete arsenal of public services. Governments can take use of increased capacity for disseminating critical information to citizens. According to research, farmers' understanding of agricultural best practices and commodity pricing can be improved by exchanging information via text messaging on those practices and prices.

\section{References}

*** (2010). Europe 2020. A strategy for smart, sustainable and inclusive growth /* COM/2010/2020 final */ Europa 2020: Strategia Uniunii Europene pentru ocuparea forței de muncă și creștere economică.

*** (2014). Strategia Naţională privind Agenda Digitală pentru România Iulie 2014. The National Strategy for the Digital Agenda for Romania, July 2014.

*** (2014). Strategia Naţională privind Agenda Digitală pentru România Iulie 2014. The National Strategy for the Digital Agenda for Romania, July 2014.

*** (2020). Digital Finance Strategy for the Eu, Communication from the Commission to the European Parliament, the Council, the European Economic and Social Committee and the Committee of the Regions, Brussels, 24.9.2020, Online: https://ec.europa.eu/transparency/ regdoc/rep/1/2020/EN/COM-2020-591-F1-EN-MAIN-PART-1.PDF.

*** (2020). What is digital financing?, Online:https://ec.europa.eu/info/business-economyeuro/banking-and-finance/digital-finance_en.

Ananda, S.; Sonal Devesh \& Anis Moosa Al Lawati (2020). What factors drive the adoption of digital banking? An empirical study from the perspective of Omani retail banking, Journal of Financial Services Marketing, Vol. 25, 14-24.

Baxter, H. (2021). Digital Finance: Security Tokens and Unlocking the Real Potential of Blockchain, 208 p., Wiley, ISBN13:9781119756309.

Benni, N. (2021) Digital finance and inclusion in the time of COVID-19: Lessons, experiences and proposals. Rome, FAO. https://doi.org/10.4060/cb2109en, http://www.fao.org/.

Bodislav, D.A., Buzoianu, O.A.C., Burlacu, S., \& Rădulescu, C.V. (2020). Analysis of companies in Romania from the perspective of risk perception and the management needs thereof. Economic Convergence in European Union, 341.

Bran, F., Rădulescu, C.V., Bodislav, D.A., \& Burlacu, S. (2020). Environmental risks in the context of globalization. Economic Convergence in European Union, 350.

Burlacu, S., Alpopi, C., Mitrită, M., \& Popescu, M.L. (2019). Sustainable e-Governance and Human Resource Development. European Journal of Sustainable Development, 8(5), 16.

Burlacu, S., Profiroiu, A., \& Vasilache, P. C. (2019). Impact of Demography on the Public Finance of the European Union. Calitatea, 20(S2), 136-138.

Ciobanu, G., Ghinăraru, C., Davidescu, A.A.M., Creţu, A.S., Chiriac, B. (2015). Aspecte ale dezvoltării economiei digitale în România: teorie, tehnici de măsurare, politici de dezvoltare şi locuri de muncă, Bucureşti:Editura Universitară, ISBN 978-606-28-0266-0.

Danchev, S., Gatopoulos, G., Vettas, N. (2020). Penetration of Digital Payments in Greece after Capital Controls: Determinants and Impact on VAT Revenues, CESifo Economic Studies, 66(3), September 2020, 198-220, https://doi.org/10.1093/cesifo/ifz019.

Flyverbom, M., Deibert, R., Matten, D. (2017). The Governance of Digital Technology, Big Data, and the Internet: New Roles and Responsibilities for Business, Business \& Society, 58(1), 3-19. 
Forte, E., Bortz, M., Burger, J., Vrabec, J., and Hasse, H. (2019). Digitalization in Thermodynamics, Chemie Ingenieur Technik, Online ISSN:1522-2640, published: 08 January 2019, https://doi.org/10.1002/cite.201800056.

Helwerda, R. (2020). Digitalisation, Industrial Revolutions and the Second Law of Thermodynamics.

Jianu, I., Dobre, I., Bodislav, D.A., Radulescu, C.V., \& Burlacu, S. (2019). The Implications of Institutional Specificities on the Income Inequalities Drivers In European Union, Economic Computation and Economic Cybernetics Studies and Research, 53(2), 59-76.

Negescu, M.D., Burlacu, S., Mitriţă, M., Buzoianu, O.C.A. (2020). Managerial Analysis of Factoring at the International Level Challenges of the Contemporary Society. Proceedings; Cluj-Napoca, 13(1), 99-102, Cluj-Napoca, Babes Bolyai University.

OECD (2018). Financial Markets, Insurance and Private Pensions: Digitalisation and Finance, http://www.oecd.org/finance/Financial-markets-insurance-pensions-digitalisation-and-fi nance.pdf.

Ogorodnikov, P. I., Zaloznaia, G. M., Borovskii, A.S. (2018). Огородников П. И., Залозная Г. М., Боровский А. С. Системный анализ обеспечения стабильности эффективного функционирования инновационной и цифровой экономики на основе интеллектуализации системы комплексной безопасности // Экономика региона. 2018. - Т. 14, вып. 4. - С. 1221-1231.

Orzan, M.C., Burlacu, S., Florescu, M.S., Orzan, O.A., \& Macovei, O.I. (2020). The effects of online marketing on financial performance in the textile industry, Industria Textila, 71(3), 288-293.

Paulin, A. (2018). Digitalisation vs. Informatization: different approaches to governance transformation, CEE e|Dem and e|Gov Days 2018, 251-260, Including a Workshop on Smart Cities organized by the Congress of Local and Regional Authorities of the Council of 2018, Budapest, Facultas 2018, ISBN-10: 3708917375, ISBN-13: 978-3708917375.

Ozili, P.K. (2018). Impact of digital finance on financial inclusion and stability, 18(4), December 2018, Borsa Istanbul Review, 329-340.

Rădulescu, C.V., Burlacu, S., Bodislav, D.A., \& Bran, F. (2020). Entrepreneurial Education in the Context of the Imperative Development of Sustainable Business, European Journal of Sustainable Development, 9(4), 93-93.

Shofawati, A. (2019). The Role of Digital Finance to Strengthen Financial Inclusion and the Growth of SME in Indonesia $2^{\text {nd }}$ ICIEBP The $2^{\text {nd }}$ International Conference on Islamic Economics, Business, and Philanthropy (ICIEBP) Theme: "Sustainability and Socio Economic Growth" Volume 2019.

Yang, L., Youtang Zhang, Y. (2020). Digital Financial Inclusion and Sustainable Growth of Small and Micro Enterprises - Evidence Based on China's New Third Board Market Listed Companies, www.mdpi.com. 